\title{
Dense and Cellular Zirconia Produced by Gel Casting with Agar: Preparation and High Temperature Characterization
}

\author{
Jean-Marc Tulliani, ${ }^{1}$ Edoardo Bemporad, ${ }^{2}$ Marco Sebastiani, ${ }^{2}$ \\ Giovanni Pulci, ${ }^{3}$ Jacopo Tirillò, $^{3}$ and Cecilia Bartuli ${ }^{3}$ \\ ${ }^{1}$ Department of Applied Science and Technology, Politecnico di Torino, INSTM Reference Laboratory for Ceramics Engineering, \\ Corso Duca Degli Abruzzi 24, 10129 Torino (To), Italy \\ ${ }^{2}$ Department of Engineering, University of "Roma Tre," INSTM Reference Laboratory for Engineering of Surface Treatments, \\ Via della Vasca Navale 79, 00146 Roma (RM), Italy \\ ${ }^{3}$ Department of Chemical Engineering Materials Environment, University of Rome "La Sapienza," INSTM Reference \\ Laboratory for Engineering of Surface Treatments, Via Eudossiana 18, 00184 Roma (RM), Italy
}

Correspondence should be addressed to Cecilia Bartuli; bartuli@uniromal.it

Received 25 January 2013; Revised 18 April 2013; Accepted 13 May 2013

Academic Editor: Rachman Chaim

Copyright (C) 2013 Jean-Marc Tulliani et al. This is an open access article distributed under the Creative Commons Attribution License, which permits unrestricted use, distribution, and reproduction in any medium, provided the original work is properly cited.

\begin{abstract}
A modified gel-casting process was developed to produce both dense and highly porous (40\% volume) yttria tetragonal zirconia polycrystal (Y-TZP) using agar, a natural polysaccharide, as gelling agent. A fugitive phase, made of commercial polyethylene spheres, was added to the ceramic suspension before gelling to produce cellular ceramic structures. The characterization of the microstructural features of both dense and cellular ceramics was carried out by FEG SEM analysis of cross-sections produced by focused ion beam. The mechanical properties of the components were characterized at room temperature by nanoindentation tests in continuous stiffness measurement mode, by investigating the direct effect of the presence of residual microporosity. The presence of a diffuse residual microporosity from incomplete gel deaeration resulted in a decay of the bending strength and of the elastic modulus. The mechanical behavior of both dense and cellular zirconia (in terms of elastic modulus, flexural strength, and deformation at rupture) was investigated by performing four-point bending tests at the temperature of $1500^{\circ} \mathrm{C}$.
\end{abstract}

\section{Introduction}

A variety of applications, such as molten metals filtration, high temperature thermal insulation, support for catalytic reactions, bone substitutes, and filtration of particulate from diesel engine exhaust gases and of hot corrosive gases in various industrial processes, require porous ceramics; thus the interest in them has rapidly grown over the last decades $[1,2]$.

The pores features directly affect most properties of the produced components. Two crucial steps are involved in the production of cellular materials with optimal, applicationtailored properties: first, the selection and set-up of a reliable and reproducible forming method, allowing for a strict control of pore size, volume, distribution, and morphology; second, an appropriate characterization procedure of both the actual porosity features and the mechanical/functional performance $[1,2]$.
Gel casting is a well-known wet forming method based on the combination of ceramic processing and polymer chemistry: a ceramic powder is dispersed into a monomer solution, prior to casting into a nonporous mold and the polymerization is then promoted. As a consequence, ceramic particles are entrapped into the rigid and homogenous polymeric network [3]. After gel formation, gel-cast green materials can be easily demolded and are then dried in controlled conditions. The produced green bodies are characterized by a high strength, allowing for good machinability, and by a low amount of organic additives, thus avoiding the requirement of preliminary thermal treatments, as in the injection molding process [4]. The technique is also versatile and has been extended to a variety of ceramic materials, such as $\mathrm{Al}_{2} \mathrm{O}_{3}$ [5], $\mathrm{Si}_{3} \mathrm{~N}_{4}$ [6], hydroxyapatite [7], $\mathrm{SiC} / \mathrm{Si}_{3} \mathrm{~N}_{4}$ composites [8], $\mathrm{ZrO}_{2}$ [9], and mullite [10]. 
Different monomers were used for gel casting, starting from acrylamide systems $[3,4,8,11]$, now withdrawn due to their neurotoxicity [12]. Alternatively, natural gelling agents were also employed, such as agar [13] and its purified derivative, agarose $[5,6,9,13,14]$, carrageenan gums [13], egg white [15], chitosan [16], gelatin [15-17], sodium alginate [18], glycerol [7], polyvinyl alcohol [17], gluten urea [19], and glucose [20].

Natural gelling agents present the advantages of a low environmental impact and of a polymerization promoted by simple cooling below the glass-transition temperature, without the use of a catalyst and an initiator, as needed for synthetic monomers.

Agar is derived from the red algae class of seaweed by a series of extraction and bleaching operations [22]; it is only soluble in hot water $\left(85-90^{\circ} \mathrm{C}\right)$ and also gels on cooling [13]. Agarose is the gelling fraction of agar [13]. These solutions are usually prepared by direct heating in a beaker but the increase in the viscosity during the melting of agarose powder limits its maximum concentration in solution to 3-4 wt\% [5]. However, in overpressure conditions, in a closed vessel at $100-115^{\circ} \mathrm{C}$, agarose solutions with a concentration of $5.6 \mathrm{wt} \%$ could be prepared [5]: solids were added to suspensions containing $0.25-2.78 \mathrm{wt} \%$ of agarose in water $[5,9]$. The burnout behavior of agar in air showed a thermal decomposition between $250^{\circ}$ and $500^{\circ} \mathrm{C}$ [22].

Gel-casting process was first set up for preparing dense components and later modified to fabricate also porous ceramics, by combining it with foaming techniques or replica methods or even by the addition of a sacrificial phase $[1,8,16$, 23].

In this paper, a modified gel-casting process was developed to produce both dense and highly porous materials (40\% volume) having controlled porosity features. A fugitive phase, made of commercial polyethylene spheres in a size range selected by sieving, was added to the ceramic suspension before gelling. The shape, size, and size distribution of these spheres as well as their volume fraction with respect to the ceramic content into the slurry can allow for a strict control of many porosity features of the final components.

The mechanical properties of the components were characterized at room temperature by nanohardness tests in continuous stiffness measurement mode, by investigating the direct effect of the presence of residual microporosity.

Finally, with the aim of assessing the potential use of gelcasting ceramics as high temperature insulators or structural components, the mechanical behavior of both dense and cellular zirconia (in terms of elastic modulus, flexural strength, and deformation at rupture) was investigated by performing four-point bending tests at the temperature of $1500^{\circ} \mathrm{C}$.

\section{Materials and Method}

2.1. Samples Preparation. Commercial stabilized zirconia containing $3 \mathrm{~mol} \%$ yttria (yttria tetragonal zirconia polycrystal, Y-TZP, grade TZ-3YS supplied by Tosoh Co., Japan) was used for preparation of ceramic suspensions. Particle size distribution was determined by means of a laser granulometer
(Fritsch Analysette 22) in ethanol after 10 minutes of ultrasonication.

Two different kinds of agar were chosen as gelling agents: gum agar, Fluka 05040, and Sigma-Aldrich 07049; they were dissolved in hot water at about $90^{\circ} \mathrm{C}$ and gelled on cooling [13]. After calcinations, the declared residual ash fraction was less or equal to 6 and 2\%, respectively, for the Fluka and the Sigma-Aldrich products, according to the technical data sheets.

In a first step, to set up the procedure, dense components were produced. With the Fluka agar, suspensions having a content of 17.02 vol\% were prepared in deionized water and Dolapix PC 33 (Zschimmer \& Schwarz, 1.14 vol\% of the overall solution) was added as a dispersant, while with the SigmaAldrich agar, suspensions having a higher solid content of 19.12 vol\% could be prepared in deionized water, keeping constant the Dolapix PC 33 content with respect to zirconia powder ( 1.28 vol\% of the overall solution). Part of the water was used to disperse the zirconia powder with Dolapix by means of a magnetic stirrer for 10 minutes and after that with an ultrasonic probe for 15 minutes. After agar addition, the solid content in the solution to be cast was $55.55 \mathrm{wt} \%$ for the Fluka product and $58.99 \mathrm{wt} \%$ for the Sigma-Aldrich product.

The agars were dissolved into the remaining part of the deionized water at $90^{\circ} \mathrm{C}$ for 1 hour $(2.38 \mathrm{wt} \%$ of agar in this suspension) and the solutions were then cooled down to $60^{\circ} \mathrm{C}$ and added to the ceramic suspensions, which were, in the meantime, warmed at the same temperature under magnetic stirring. Several tests were carried out to determine the optimal agar amount: starting from $1 \mathrm{wt} \%$ and reducing its content down to $0.74 \mathrm{wt} \%$, with respect to water. Agar tends to produce foam under stirring, a well-known phenomenon for organic materials but also with water soluble polymers belonging to the acrylamide family [10]. Then, suspensions containing the Fluka agar were cast under vacuum (at about $10^{-2} \mathrm{~Pa}$ ), while those containing the Sigma agar, due to their lower viscosity, were added with some drops of poly(ethylene) glycol (PEG) as antifoaming agent, prior to casting into Plexiglas molds at about $50^{\circ} \mathrm{C}$. In this case, no deairing step was performed, except for molds tapping to remove air bubbles entrapped into the ceramic suspensions. The casting temperature was selected as an optimal compromise between the low viscosity necessary for suspensions casting and the agar gelling point $\left(36^{\circ} \mathrm{C}\right)$. The suspensions viscosity was determined by means of a Brookfield DVII+ viscosimeter with an ULA-EY UL adapter for the measurement of low viscosity liquids.

The cast samples (in the shape of $10 \times 12 \times 94 \mathrm{~mm}^{3}$ bars) were slowly dried at room temperature under controlled humid atmosphere and then, after demolding, in static air.

The linear drying shrinkage was about $9 \%$, whatever the agar used for samples preparation.

A polyethylene (PE) powder, supplied by Clariant Italia $\mathrm{SpA}$, having a density at $23^{\circ} \mathrm{C}$ of about $0.92-0.94 \mathrm{~g} / \mathrm{cm}^{3}$, was used as fugitive phase to produce cellular ceramics. Its thermal decomposition is almost completed after calcination at $550^{\circ} \mathrm{C}$ [24]. PE powder was made of almost spherical particles, but irregular structures were also present $[25,26]$. 
Polyethylene spheres were first sieved in the range 125$300 \mu \mathrm{m}$, before dispersion into ceramic suspensions. It must be also noted that during sieving few smaller particles remained adherent to the larger ones, so that a limited fraction of pores smaller than those expected from the sieved range could be observed in the final materials [27].

To fabricate porous ceramics, PE spheres were dispersed in water, in suitable amounts to obtain zirconia suspensions having $50 \mathrm{vol} \%$ polymers, leading to samples that will be indicated as P50. The ceramic content of the slurries in the samples P50 was slightly lower with respect to the dense materials ( 16.95 vol\%, before PE addition) to keep a suitable viscosity of the suspension for casting. On the contrary, the agar content was kept constant with water fraction and was the same as for the dense samples.

Dense-gel cast zirconia ceramics were sintered at $1550^{\circ} \mathrm{C}$ (heating at a rate of $1^{\circ} \mathrm{C} / \mathrm{min}$, holding for 2 hours at $600^{\circ} \mathrm{C}$, to complete agar decomposition, and then a second heating step at a rate of $1^{\circ} \mathrm{C} / \mathrm{min}$ to the maximum temperature for 1 or 2 hours and cooling rate of $5^{\circ} \mathrm{C} / \mathrm{min}$ down to room temperature). The sintering cycle was set up on the ground of mercury intrusion porosimetry measurements studies performed on gel cast bars.

Cellular samples were heated to $450^{\circ} \mathrm{C}$ and then sintered following a different thermal cycle. Various intermediate steps, on the basis of the TGA results [28], were introduced to control the thermal decomposition of the polyethylene spheres without collapsing the structure; the following cycle was adopted: a constant heating ramp of $1^{\circ} \mathrm{C} / \mathrm{min}$, with a first holding time of 10 hours at $230^{\circ} \mathrm{C}$, and a second plateau at $300^{\circ} \mathrm{C}$ for 2 hours, followed by a third one at $450^{\circ} \mathrm{C}$ for 2 hours and a last one at $600^{\circ} \mathrm{C}$ for 2 hours. Also in the final sintering phase an isothermal treatment at $1360^{\circ} \mathrm{C}$ for two hours was introduced before final sintering at $1550^{\circ} \mathrm{C}$ for two hours. All samples were then cooled down to room temperature with a cooling rate of $5^{\circ} \mathrm{C} / \mathrm{min}$.

\subsection{Mechanical Characterization. Nanoindentation tests} were performed by means of a Berkovich diamond indenter, using an Agilent G200 Nano Indenter machine, in a continuous stiffness measurement mode (CSM) under a constant strain rate of $0.05 \mathrm{~s}^{-1}$ and a maximum load of $650 \mathrm{mN}$ (other test and fitting parameters were chosen according to ISO 14577-1-2 standards). The contact stiffness is dynamically measured during indentation, as the indenter is driven in during loading, and continuous hardness/depth and modulus/depth curves are then obtained. Elastic modulus and hardness are then accessible without direct imaging of the indentation [29]. The hardness $H$ is derived by

$$
H=\frac{P_{\max }}{A},
$$

where $A$ is the indenter projected contact area, which is given as a polynomial function of the contact depth $h_{c}$, for a Berkovich indenter [29]:

$$
A=a_{0} h_{c}^{2}+a_{1} h_{c}+a_{2} h_{c}^{1 / 4}+a_{3} h_{c}^{1 / 8}+\cdots
$$

with the contact depth being defined as follows [28]:

$$
h_{c}=h-\eta \frac{P}{S} \text {. }
$$

The coefficient $\eta$ can range between 0.72 and 1 ; a value of 0.75 is usually adopted for Berkovich indenter [29].

The contact area expressed in (2) is finally evaluated by calibration on certified fused silica reference sample, performed before and after each series of tests on dense zirconia.

The reduced elastic modulus is calculated by the following equation $[30,31]$ :

$$
E_{r}=\frac{\sqrt{\pi}}{2 \beta} \cdot \frac{S}{\sqrt{A}},
$$

where $S=d P / d h$ is the elastic contact stiffness evaluated, after fitting the upper portion (usually 50\%) of the unloading curve to a power-law relation (Oliver-Pharr method, [32]), as the slope of the unloading curve at maximum load $P_{\max } ; \beta$ is a numerical factor equal to 1.034 for a Berkovich indenter, related to a lack of symmetry of the indenter [30]. As recently reviewed by Oliver and Pharr [32], values in the range of $1.0226 \leq \beta \leq 1.085$ can be found in the literature; in the present work a value of 1.000 was adopted, as suggested by the ISO 14577-1-2 standard. However, recent studies [33] have underlined that further corrections factors should be adopted.

The Elastic modulus of the tested samples can then be estimated by

$$
\frac{1}{E_{r}}=\frac{(1-v)^{2}}{E}+\frac{\left(1-v_{i}\right)^{2}}{E_{i}},
$$

where $E_{i}$ and $v_{i}$ are, respectively, the Young's modulus and the Poisson ratio of the indenter.

In all cases, the cross-sections of the samples were polished before the indentations by means of diamond lapping films in 15, 6, 3, and 1 microns grades, each for one minute.

Mechanical behavior of dense and porous samples, in terms of elastic modulus, flexural strength, and deformation at rupture, was also investigated by means of four-point bending tests performed at room and high temperature $\left(1500^{\circ} \mathrm{C}\right.$ in air).

The tests were carried out on parallelepiped shaped specimens $(45 \times 4 \times 3 \mathrm{~mm})$ by means of a Zwick-Roell Z2.5 testing machine equipped with a Maytec furnace (up to $1600^{\circ} \mathrm{C}$ ), a 3-point-contact extensometer (autocompensating for thermal strain), and a silicon carbide flexure device.

Testing parameters were selected according to ASTM C1161: "Standard Test Method for Flexural Strength of Advanced Ceramics at Ambient Temperature" and ASTM C1211-02(2008): "Standard Test Method for Flexural Strength of Advanced Ceramics at Elevated Temperatures". Bending tests were performed using a cross-head rate of $0.5 \mathrm{~mm} / \mathrm{min}$. Samples were placed in the furnace at room temperature and the temperature of the furnace was then raised at the rate of $10^{\circ} \mathrm{C} / \mathrm{min}$, with a dwell time of 30 minutes at testing temperature before the test start. 


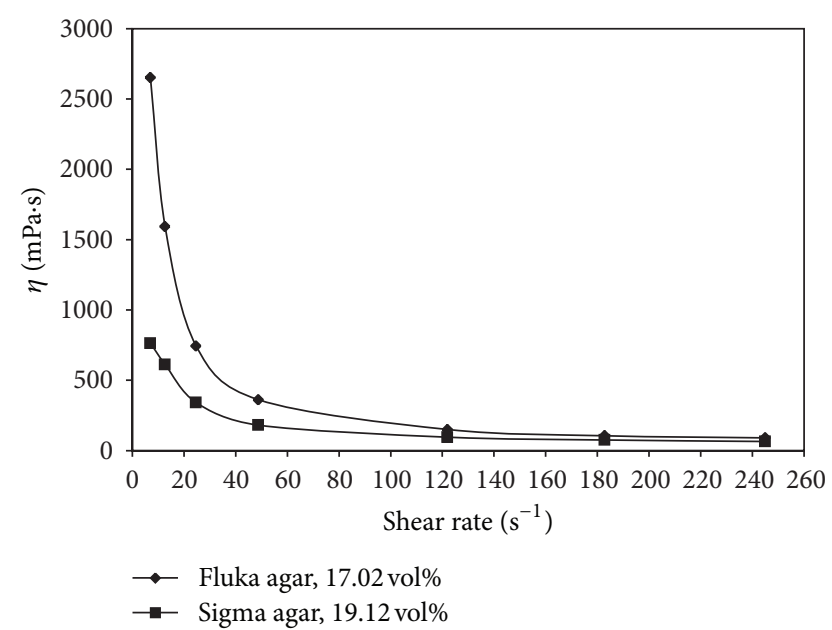

FIGURE 1: Viscosity of the ceramic slurry as a function of shear rate.

In view of preparation and observation of vertical sections by the Focus Ion Beam (FIB), the surfaces were first mirror polished, then etched with $\mathrm{Ga}^{+}$, and sputtered with a thin film of platinum $(2 \mu \mathrm{m})$ to protect the zones which were not crosssectioned.

\section{Results}

3.1. Powders Characterization. After 10 minutes sonication in an ultrasonic bath, the mean diameter of the zirconia powder was about 0.6 micron and the diameters corresponding to $10 \%$ and $90 \%$ of the particle size distributions were, respectively, 0.33 and 1.1 micron.

A pellet of pure agar was uniaxially pressed at $100 \mathrm{MPa}$ and heated up to $600^{\circ} \mathrm{C}$ for 2 hours, to evaluate the solid residue which was estimated around 3.9\% and $0.8 \mathrm{wt} \%$, respectively, for the Fluka and Sigma agar.

Suspensions having a solid loading of $17.02 \mathrm{vol} \%$ with the Fluka agar and 19.12 vol\% with the Sigma agar were prepared as previously described and their viscosity determined at $53^{\circ} \mathrm{C}$ (Figure 1).

The Sigma agar allowed for preparing suspensions with a higher solid content and with a lower viscosity than Fluka agar. Moreover, casting of the suspensions prepared with the Fluka agar was rather difficult: their viscosity, under a shear rate of $20 \mathrm{~s}^{-1}$, was around $900 \mathrm{mPa} \cdot \mathrm{s}$, a value close to the viscosity limit reported in the literature (1000 mPa.s [15]).

3.2. Dense Samples. Dense samples fired at $1450^{\circ} \mathrm{C}$ for 1 hour showed a geometrical density of $80 \pm 1 \%$, while firing at $1550^{\circ} \mathrm{C}$ for 1 hour allowed for reaching a density of $87 \pm 1 \%$ (average value on 5 bars prepared with the Fluka agar and 5 bars made with the Sigma agar, assuming the theoretical density of the zirconia equal to $6.05 \mathrm{~g} / \mathrm{cm}^{3}$ ). On five bars, prepared with the Fluka agar, the bending strength was evaluated to be $230.0 \pm 66.5 \mathrm{MPa}$ and the elastic modulus was $137.8 \pm 4.8 \mathrm{GPa}$. However, due to the fact that the solid content was lower and to the casting difficulties, the use of Fluka agar was abandoned.

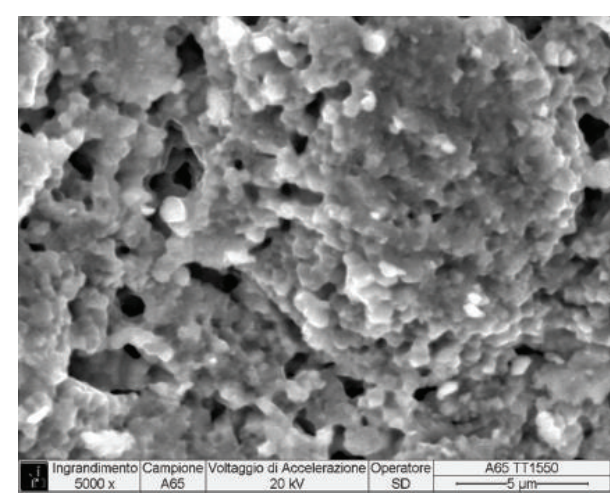

(a)

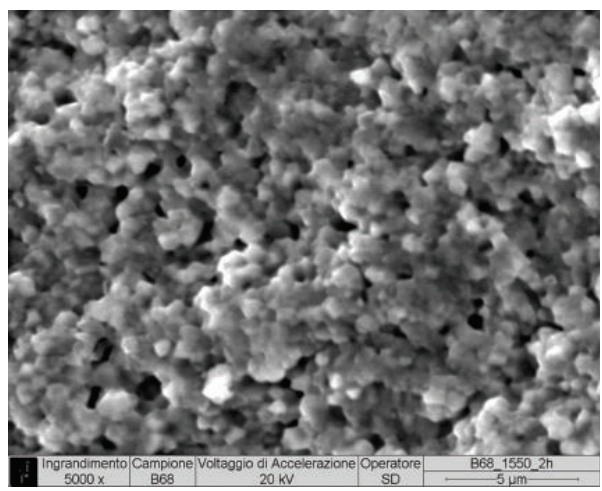

(b)

FIgURE 2: SEM micrographs of a fracture surface of a dense $\mathrm{ZrO}_{2}$ sample sintered at $1550^{\circ} \mathrm{C}$ for 1 hour (a) and 2 hours (b).

TABLE 1: Total porosity and mean pore diameter on samples sintered at $1550^{\circ} \mathrm{C}$ for one (B65) or two hours (B68).

\begin{tabular}{lll}
\hline Sample & B65 & B68 \\
\hline Total porosity $(\%)$ & 6.82 & 0.47 \\
Mean pore diameter $(\mu \mathrm{m})$ & 7.84 & 0.72 \\
\hline
\end{tabular}

The samples prepared with the Sigma agar were characterized by a diffused porosity (Figure $2(\mathrm{a})$ ), which was drastically reduced with a holding time of 2 hours at sintering temperature (Figure 2(b)), as also confirmed by mercury intrusion porosimetry measurements (Table 1).

This porosity seems to be characteristic of the process and has been evidenced also on dense alumina samples prepared with a higher solid content (20 vol\%) [34].

The longer plateau at $1550^{\circ} \mathrm{C}$ allowed the geometrical density to increase up to $93.4 \pm 1.2 \%$ (average values). Therefore, on this basis, the thermal treatment at $1550^{\circ} \mathrm{C}$ for $2 \mathrm{~h}$ was chosen for all the samples. Table 2 reports the flexural strength and the elastic modulus of the dense prisms at room temperature calculated by means of four-point bending tests.

FEG-SEM observations of a fracture surface from sample F65, after flexural test, revealed submicron grains and small porosities, some of them elongated, of about $2 \mu \mathrm{m}$ length (Figure 3). On the same sample, mirror polished, FEG-SEM observations after FIB cross-sections confirmed the presence of diffused subsurface microporosity (Figure 4). 
TABLE 2: Results of four-point bending tests performed at room temperature on dense and porous samples (average values \pm standard deviation).

\begin{tabular}{lccc}
\hline Sample & $\begin{array}{c}\text { Density } \\
(\%)\end{array}$ & $\begin{array}{c}\text { Modulus of rupture } \\
(\mathrm{MPa})\end{array}$ & $\begin{array}{c}\text { Elastic modulus } \\
(\mathrm{GPa})\end{array}$ \\
\hline Dense samples & $93 \pm 1$ & $413 \pm 110$ & $170 \pm 6$ \\
Porous samples & $61 \pm 2$ & $33 \pm 11$ & $44 \pm 9$ \\
\hline
\end{tabular}

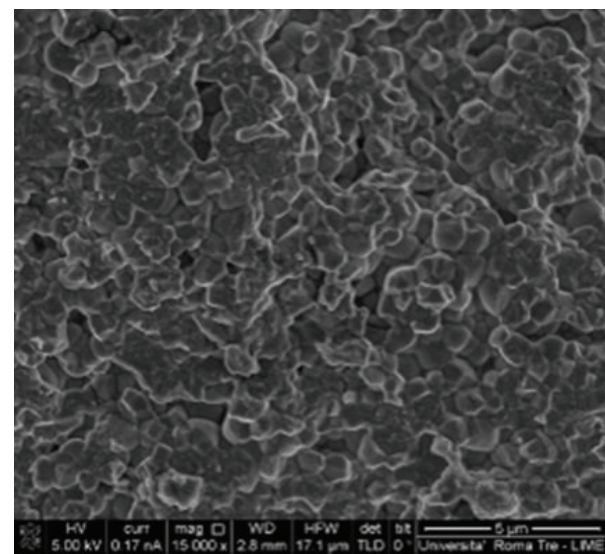

(a)

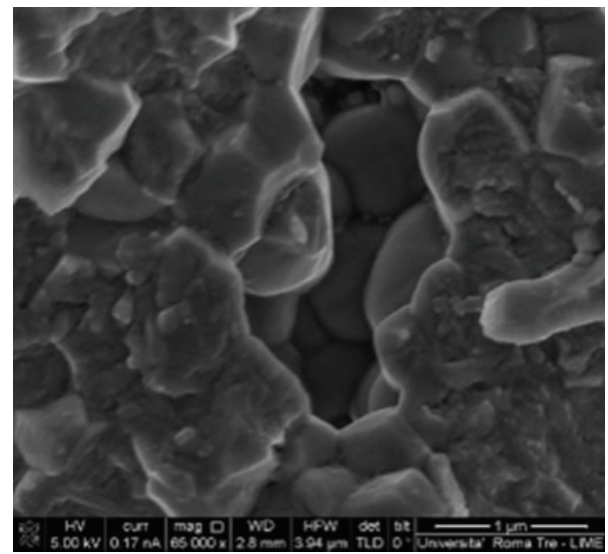

(b)

FIGURE 3: SEM micrographs of a fracture surface of a dense sample (F65) after flexural test.

On the same sample, mirror polished, 12 nanoindentation tests in a continuous stiffness measurement mode (Figure 5) were carried out using a Berkovich indenter, to evaluate hardness and elastic modulus of the sample. Results are resumed in Table 3. Figure 6 reports Young modulus of the material as a function of the indenter penetration, assuming a Poisson ratio of 0.3 (statistical processing of the 12 indentations), and shows the increasing effect of porosity with increasing depth.

The high temperature mechanical behavior of two dense samples (C68, B64) was evaluated by means of high temperature four-point bending tests (at $1500^{\circ} \mathrm{C}$, after a dwell time of 30 minutes). In Figure 7 the stress-strain curve corresponding to the test of C68 dense sample is shown in solid black line.

Both samples clearly exhibited a high temperature plastic behavior: neither the modulus of rupture nor the strain at

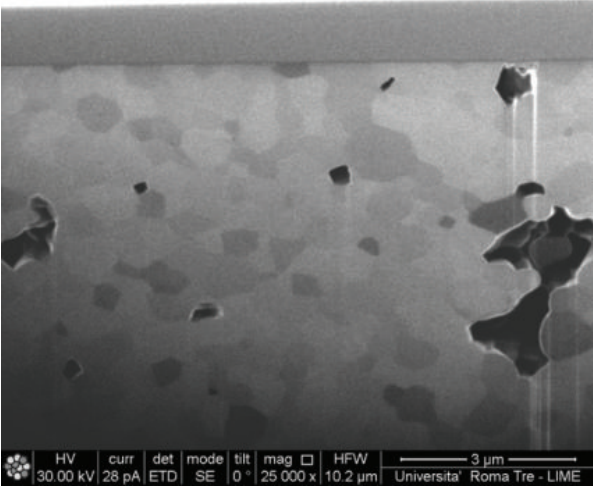

(a)

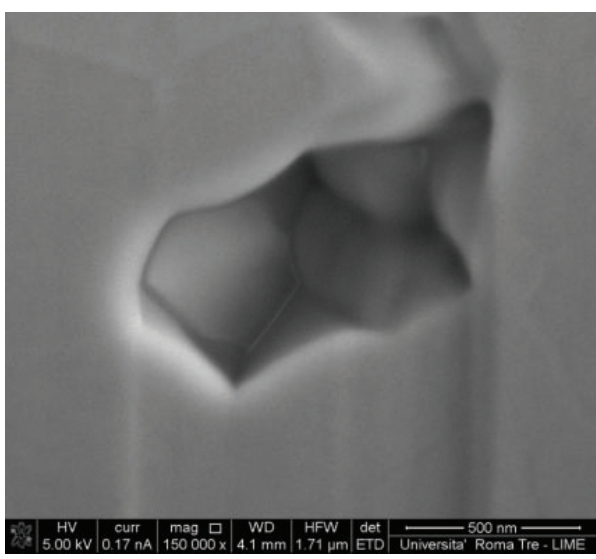

(b)

FIGURE 4: SEM micrographs of FIB cross-section of dense F65 sample showing subsurface microporosity.

break of the dense samples could be evaluated, because during the test the specimens reached the maximum deformation allowed by the four-point bending apparatus without coming to final rupture, as shown in Figure 8. The elastic modulus of dense samples, calculated in the linear zone of the stressstrain curve, has an average value of $28 \mathrm{GPa}$.

Cross-sections observations by means of the FIB were performed on tested samples along the $y-z$ plane, in the center zone corresponding to the maximum bending moment (Figure 9). On this surface, two cross-sections were created: one perpendicular to the $y$ axis and the other orthogonal to the $z$ plane, in order to identify the presence of any microstructural difference.

SEM observations did not confirm any significant microstructural difference between the two directions of the FIB cross-sections (see Figure 10) but offered evidence of grain growth during the test: diameter of grains after the test increased to $200-1000 \mathrm{~nm}$. Pores revealed a radius curvature in the range of $10-50 \mathrm{~nm}$ and some elongated pores were evidenced in the $x$ direction, corresponding to the tensile strength direction.

On the mirror polished surface of the high temperature flexural test sample, 12 CSM nanoindentation tests were carried out (Table 3 ) to evaluate hardness and elastic modulus 


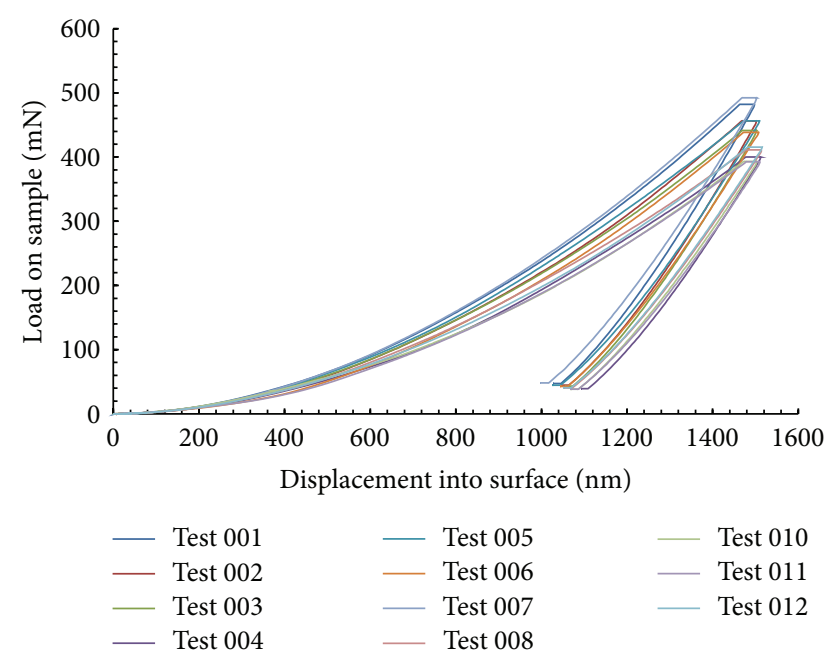

FIGURE 5: Load-displacement curves from CSM indentations of the dense sample.

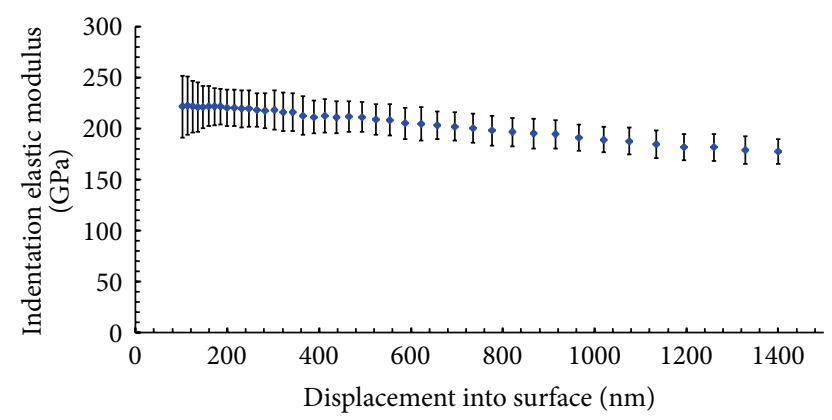

FIGURE 6: Young modulus as a function of indenter penetration for a dense sample, assuming a Poisson ratio of 0.3 (statistical processing of 12 indentations).

TABLE 3: Hardness and elastic modulus for dense and porous samples as calculated from nanoindentation tests (average values \pm standard deviation).

\begin{tabular}{lccc}
\hline Sample & $\begin{array}{c}\text { Average } \\
\text { hardness } \\
(\mathrm{GPa})\end{array}$ & $\begin{array}{c}\text { Average } \\
\text { modulus } \\
(\mathrm{GPa})\end{array}$ & $\begin{array}{c}\text { Depth range } \\
\text { considered for } \\
\text { averaging }(\mathrm{nm})\end{array}$ \\
\hline F65 & $13.9 \pm 1.6$ & $207.7 \pm 15.1$ & $200-1200$ \\
C68 tensile & $14.8 \pm 0.7$ & $221.9 \pm 8.0$ & $200-1200$ \\
C68 compressive & $14.3 \pm 1.3$ & $210.0 \pm 13.1$ & $200-1200$ \\
I44 & $14.8 \pm 0.9$ & $211.1 \pm 5.4$ & $200-1200$ \\
\hline
\end{tabular}

along the direction of the tensile and of the compressive strength.

3.3. Porous Samples. The porous samples of the series $P 50$ presented a geometrical density (as measured by mercury intrusion porosimeter) of $61 \pm 2 \mathrm{~g} / \mathrm{cm}^{3}$ after thermal treatment (Table 2). Macropores were rather homogeneously distributed within the ceramic fired material (Figure 11(a)). A diffused microporosity was also evidenced (Figure 11(b)).
TABLE 4: Results of high temperature $\left(1500^{\circ} \mathrm{C}\right)$ bending test on porous sample.

\begin{tabular}{lccc}
\hline Sample & $\begin{array}{c}\text { Modulus of } \\
\text { elasticity }(\mathrm{GPa})\end{array}$ & $\begin{array}{c}\text { Modulus of } \\
\text { rupture }(\mathrm{MPa})\end{array}$ & $\begin{array}{c}\text { Maximum } \\
\text { strain }(\%)\end{array}$ \\
\hline E46 porous & 6.4 & 22.9 & 3.4 \\
\hline
\end{tabular}

Results of the room temperature mechanical characterization (modulus of rupture and elastic modulus) performed by four-point bending tests are also summarized in Table 2 .

SEM observations, after FIB cross-sectioning of a P50 bar (I44), revealed submicronic grains and subsurface porosity characterized by low curvature radii (Figure 12).

Results of 12 nanoindentations performed on sample I44 are summarized in Table 3. The analysis of elastic modulus and hardness as a function of penetration depth was carried out also for porous samples, without evidencing peculiar behaviors.

The effect of the presence of subsurface micropores can be appraised by comparing the results of hardness profiles as a function of indentation depth for two different zones of the same sample, respectively, in the presence and in the absence of microporosity in the immediate vicinity of the indentation print, as reported in the two curves of Figure 13.

The high temperature mechanical behavior of a porous sample (E46) was also evaluated by means of four-point bending tests at $1500^{\circ} \mathrm{C}$ (see the grey curve in Figure 7). Especially in this case, the test provides interesting information and delivers data on porous ceramics typically not available in the literature: Table 4 summarizes the high temperature results.

\section{Discussion}

Dense ceramics fabricated by gel casting with agar exhibit slightly lower values of hardness and elastic modulus as compared to similar ceramics produced in a previous work from the same zirconia-yttria powders using gelatin as gelling agent [25].

As suggested by the reported results, the presence of some sub-surface microporosity, as evidenced by porosimetry and confirmed by SEM analysis of FIB cross-sections, is most likely the main cause of this deviation.

The measured elastic modulus of the dense samples (170 $\pm 6.3 \mathrm{GPa}$ ) are in the same range of those found in the literature for $7 \%$ porous samples produced from a Y-TZP nanopowder with $3 \mathrm{~mol} \%$ yttria, in accordance with the porosity dependence of elastic moduli reported in [33]:

$$
\begin{gathered}
M=216 e^{(-3.69 P)}, \\
M=210.6(1-P)^{2.96}, \\
M=214.6\left(1-3.3 P+3.54 P^{2}\right) .
\end{gathered}
$$

Bending strength is however lower $(413 \pm 110 \mathrm{MPa})$ than those reported in [35] for a $10 \%$ porous sample produced by uniaxial compaction from 3Y-TZP nanopowders (where values of $570 \mathrm{MPa}$ are reported). 


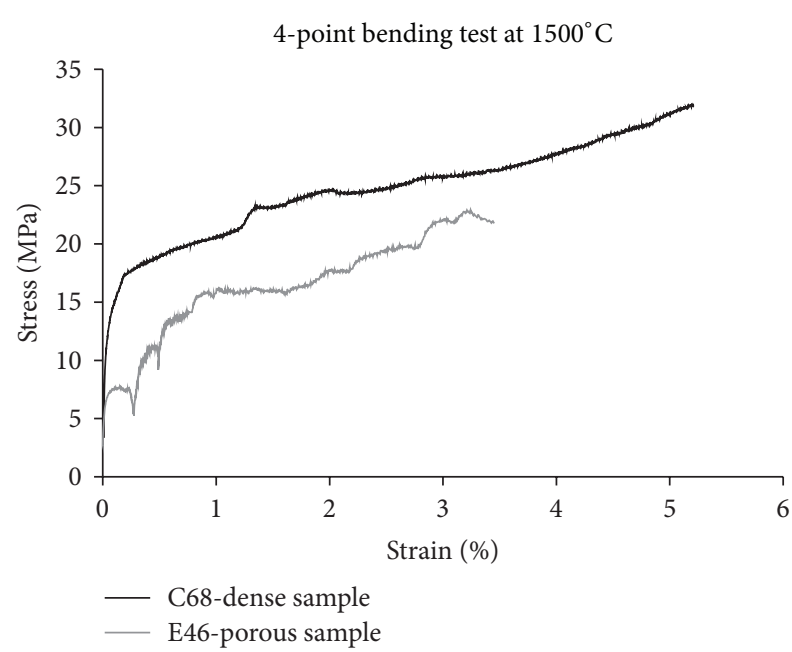

FIGURE 7: High temperature stress-strain curves for ceramic samples tested at high temperature $\left(1500^{\circ} \mathrm{C}\right)$ after $30 \mathrm{~min}$ of high temperature exposure.

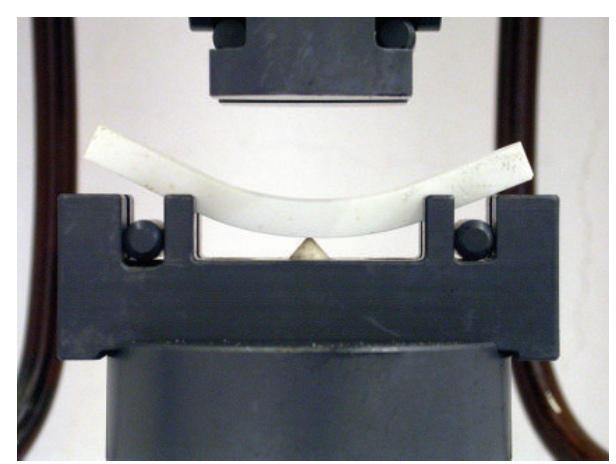

Figure 8: Dense sample C68 after high temperature $\left(1500^{\circ} \mathrm{C}\right)$ bending test: significant plastic deformation of the sample occurred, and the test was terminated without rupture.

These results can be explained by the critical effect of defects present in the prepared samples, where elongated pores with a length of 1-2 microns and a radius curvature of $10-50 \mathrm{~nm}$ being evidenced.

Residual microporosity can generally be explained by either an incomplete agar dissolution or by an insufficient deairing step $[9,10]$. In our case, the agar solution was completely clear after 1 hour at $90^{\circ} \mathrm{C}$, and the presence of microporosity is rather to be assigned to incomplete de-airing step.

High temperature four-point bending tests demonstrated that both dense and porous zirconia samples exhibited an evident plastic behavior (Figure 8). Fine grained Y-TZP ceramics are well-known high temperature superplastic materials [3640], and the high temperature stress-strain relation evidenced by the experiments can be considered as a confirmation of expected result: the strain rate imposed in the performed bending tests (about $10^{-4} / \mathrm{s}$ for dense samples) is in fact compatible with the strain rate measured in the mentioned creep tests of superplastic Y-TZP [35-40].

Several deformation mechanisms have been suggested, investigated, and modeled in the previously mentioned

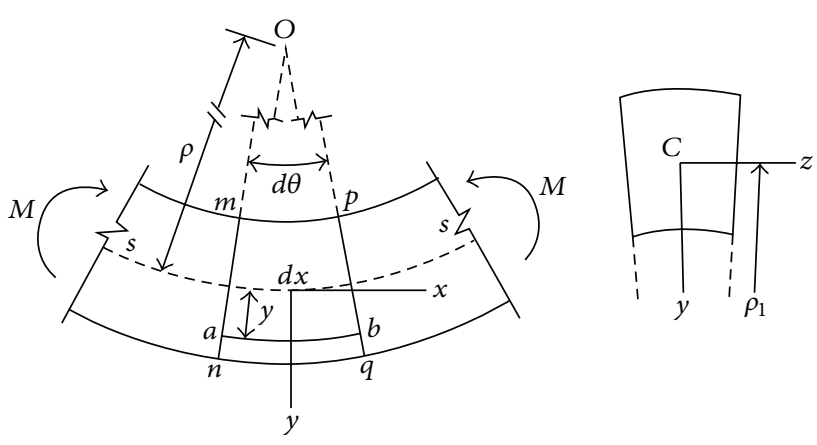

(a)

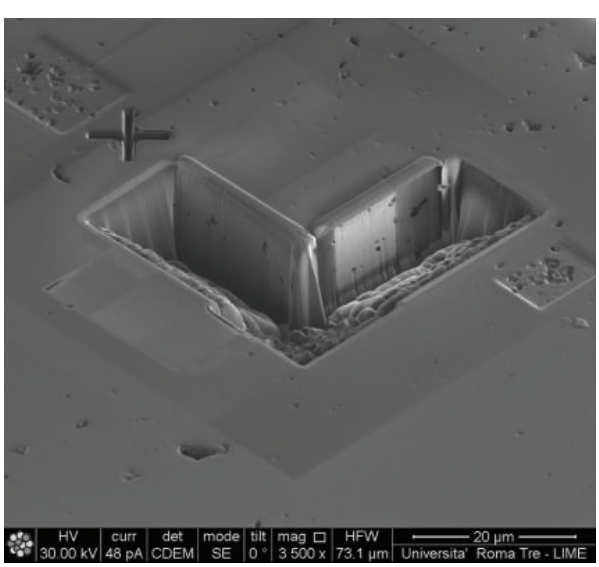

(b)

FIGURE 9: Orientation of the FIB cross-sections on samples exposed to three-point bending test ((a), [21]) ((b), real sample).

papers: superplasticity has been attributed to grain boundary sliding, intragranular dislocation creep, diffusion creep, and interface reaction controlled diffusion creep. The FEG-SEM and FIB microstructural analysis performed on dense samples tested at $1500^{\circ} \mathrm{C}$ revealed the absence of grain elongation, a substantial grain growth (from a grain size of $100-500 \mathrm{~nm}$ for samples tested at room temperature to $200-1000 \mathrm{~nm}$ after the high temperature test), and a grain boundary coalescence of porosity. The retained grain shape and the coalescence of pores allow for assuming a grain boundary sliding mechanism. Moreover, SEM images of samples tested at high temperature (see Figure 14, after thermal etching) suggest the occurrence of an intragranular dislocation mechanism, as wasalso reported in previous works [40].

It is important to remind that, even though the agar used was purified, the residual ashes can still contain traces of alkaline, chloride, and sulfur impurities, due to the extraction process [13]: the presence of impurities is a well-known key issue able to affect the creep behavior of superplastic YTZP [36-40] and could therefore have represented a further contribution to the observed deformation behavior.

Finally, it is interesting to analyze the difference between the high temperature behavior of dense and porous materials. As expected, the $40 \%$ porous zirconia exhibits a lower elastic modulus (about 6.4 versus $28 \mathrm{GPa}$ ) and a lower maximum stress (about $23 \mathrm{MPa}$ ); moreover it breaks at a strain of about $3.4 \%$, whereas dense samples are deformed to the maximum 


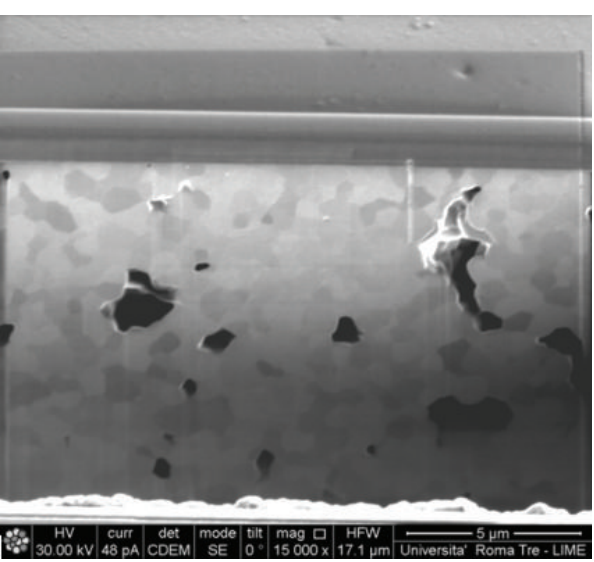

(a)

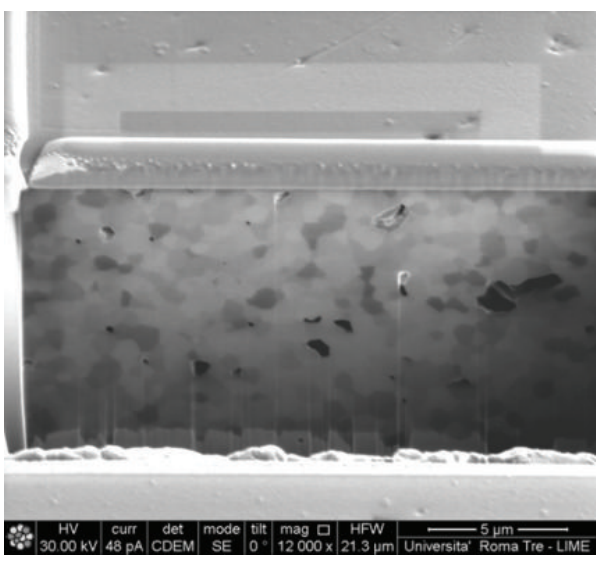

(c)

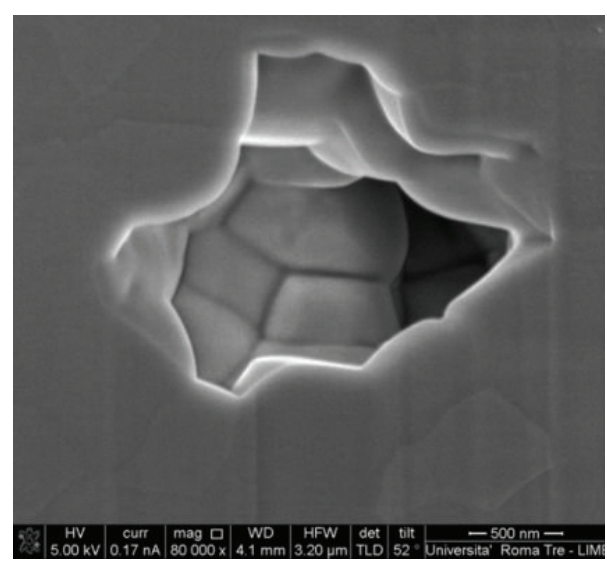

(b)

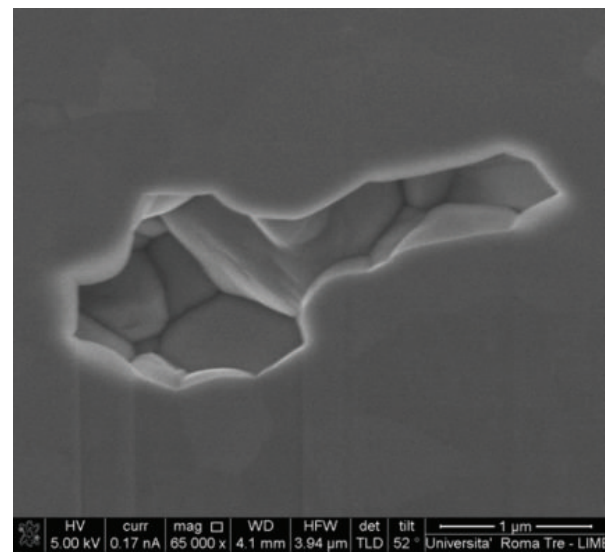

(d)

FIGURE 10: SEM micrograph: cross-section perpendicular to the $y$-axis ((a), (b)) and perpendicular to the $z$-axis ((c), (d)).

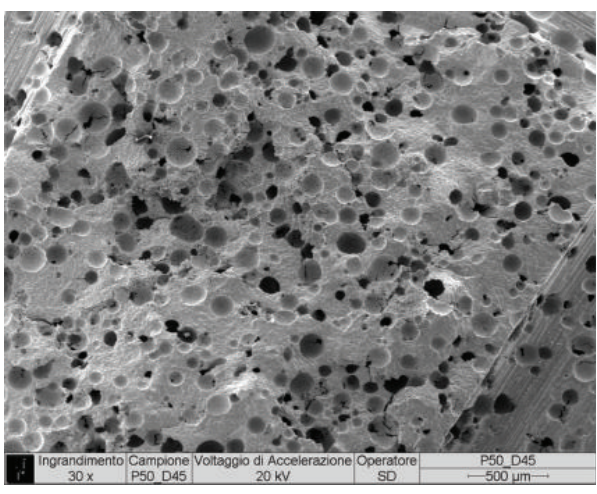

(a)

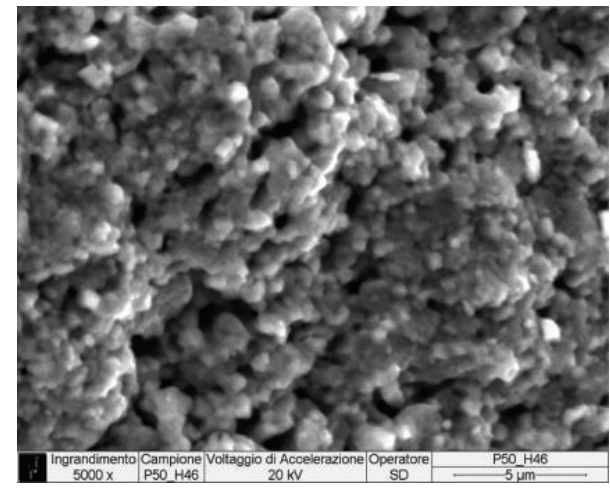

(b)

Figure 11: SEM micrograph of fracture surfaces of a P50 sample sintered at $1360^{\circ} \mathrm{C}$ for two hours and at $1550^{\circ} \mathrm{C}$ for two hours: low magnification (30x, (a)), high magnification (5000x, (b)).

allowable strain without breaking. The shape of the stressstrain curves evidences different behavior for dense and porous samples: dense samples show a continuous increase of deformation with increasing stress, while the porous material exhibits several sudden drops and rises of the load, referable to the cellular microstructure, responsible for both generating and interrupting cracks and flaws during the high temperature mechanical test.

Berkovich nanoindentation performed on the samples tested at high temperature showed no significant difference in the two directions of loading. On the other hand, the influence of the subsurface porosity on hardness and elastic 


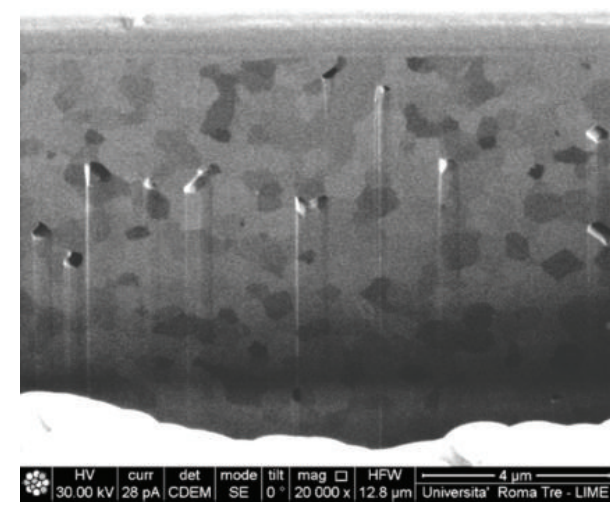

(a)

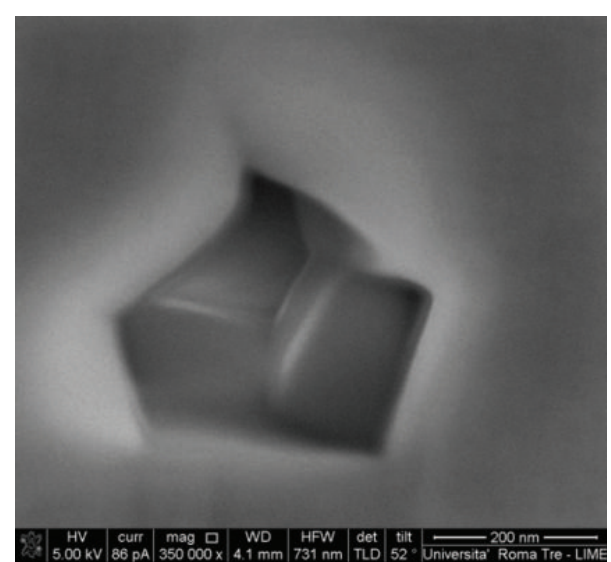

(b)

FIGURE 12: SEM micrographs of FIB cross-section of a P50 sample (I44) evidencing submicrometric grains and subsurface microporosity.

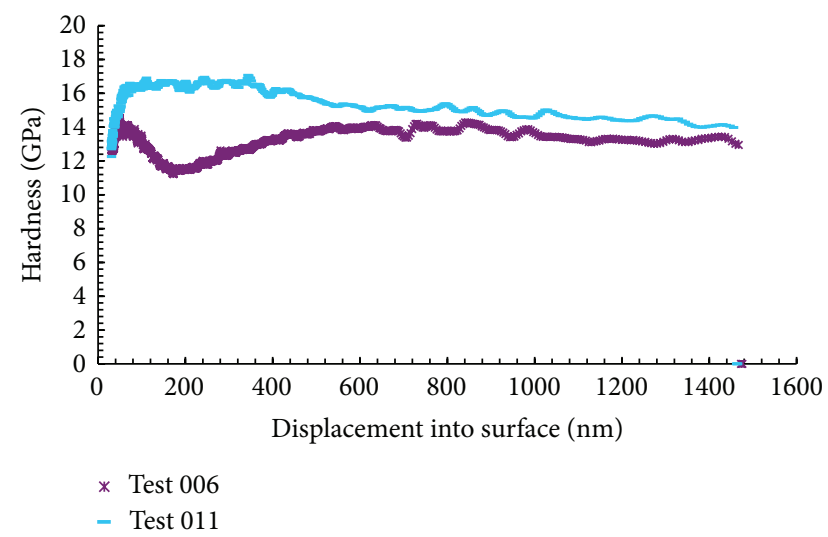

FIGURE 13: Hardness as a function of the indenter in the presence (test 6) and in the absence (test 11) of subsurface microporosity.

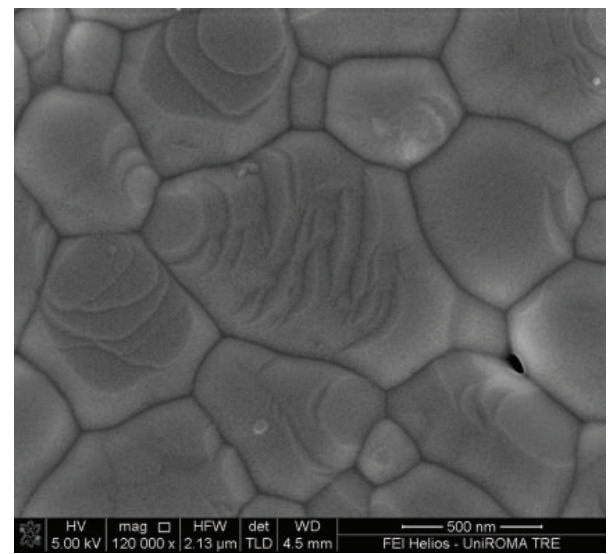

FIgURE 14: Microstructure of high temperature tested dense sample (C68).

modulus values has been confirmed, as for the sample tested at ambient temperature.

Concerning P50 samples, the average elastic modulus was $44 \pm 9 \mathrm{GPa}$, which was a bit lower as compared to the value predicted by the empirical equations (6) (values ranging from 50.1 to $52.3 \mathrm{GPa}$ are expected). Also the modulus of rupture $(33 \pm 11 \mathrm{MPa})$ was lower with respect to [35].

These results can be most likely explained considering that when the porosity content overcomes critical values of about $25 \%$ percolation starts and increasingly oblate open pores are formed [41].

Moreover, the polyethylene spheres used as forming agents are larger and more irregular in shape $[25,26]$ as compared to the more regular PMMA used in [35].

\section{Conclusions}

Both dense and macroporous 3Y-TZP samples were successfully produced by means of a gel-casting process based on agar as gelling agent.

The density of samples produced without forming agents did not overcome values of about $94 \%$, in the absence of a de-airing step under vacuum.

The addition of an antifoaming agent to the slurries could not guarantee the complete removal of all entrapped air from within the suspension, and a certain amount of small air bubbles resulted in undesirable residual porosity, as could be evidenced by FIB cross-sections FEG-SEM observation. The microporosity was the cause of a certain decay of the bending strength and of the elastic modulus of the dense ceramic components.

By addition of a sacrificial phase made of polyethylene spheres, it was possible to produce about $40 \%$ porous samples characterized by a good dispersion of the macropores, thanks to the control of the casting conditions. The flexural strength and the Young's modulus of the porous samples were slightly lower than those found in the literature for similar materials produced by more conventional routes, due to the presence of small amounts of the residual microporosity, caused by inefficient de-airing and by irregularities of the polyethylene beads.

The resistance of the sintered material as measured by nanoindentations (both in terms of nanohardness and elastic 
modulus) has been found to be very similar for dense and macroporous samples.

The high temperature mechanical tests of the material, carried out at temperatures very close to the sintering temperature (showing evident plasticity, modulus of $28 \mathrm{GPa}$ for dense samples and $6.4 \mathrm{GPa}$ for $40 \%$ porous samples), allow for assessing the potential limits of high temperature applications.

\section{Acknowledgments}

The authors wish to acknowledge Daniele de Felicis for technical assistance during FIB experiments. FIB and nanoindentation analyses were performed at the interdepartmental laboratory of electron microscopy of University of "Roma TRE," Rome, Italy.

\section{References}

[1] A. R. Studart, U. T. Gonzenbach, E. Tervoort, and L. J. Gauckler, "Processing routes to macroporous ceramics: a review," Journal of the American Ceramic Society, vol. 89, no. 6, pp. 1771-1789, 2006.

[2] P. Colombo, "Conventional and novel processing methods for cellular ceramics," Philosophical Transactions of the Royal Society A, vol. 364, no. 1838, pp. 109-124, 2006.

[3] O. O. Omatete, M. A. Janney, and R. A. Strehlow, "A new ceramic forming process," American Ceramic Society Bulletin, vol. 70, no. 10, pp. 1641-1649, 1991.

[4] A. C. Young, O. O. Omatete, M. A. Janney, and P. A. Menchhofer, "Gelcasting of alumina," Journal of the American Ceramic Society, vol. 74, no. 3, pp. 612-618, 1991.

[5] I. Santacruz, M. I. Nieto, and R. Moreno, "Alumina bodies with near-to-theoretical density by aqueous gelcasting using concentrated agarose solutions," Ceramics International, vol. 31, no. 3, pp. 439-445, 2005.

[6] A. J. Millán, M. I. Nieto, and R. Moreno, "Aqueous injection moulding of silicon nitride," Journal of the European Ceramic Society, vol. 20, no. 14-15, pp. 2661-2666, 2000.

[7] H. K. Varma and R. Sivakumar, "Dense hydroxy apatite ceramics through gel casting technique," Materials Letters, vol. 29, no. 1-3, pp. 57-61, 1996.

[8] W. Zhang, H. Wang, and Z. Jin, "Gel casting and properties of porous silicon carbide/silicon nitride composite ceramics," Materials Letters, vol. 59, no. 2-3, pp. 250-256, 2005.

[9] E. Adolfsson, "Gelcasting of zirconia using agarose," Journal of the American Ceramic Society, vol. 89, no. 6, pp. 1897-1902, 2006.

[10] D. Kong, H. Yang, S. Wei, D. Li, and J. Wang, "Gel-casting without de-airing process using silica sol as a binder," Ceramics International, vol. 33, no. 2, pp. 133-139, 2007.

[11] J. Sun and L. Gao, "Influence of forming methods on the microstructure of 3Y-TZP specimens," Ceramics International, vol. 29, no. 8, pp. 971-974, 2003.

[12] M. A. Janney, O. O. Omatete, C. A. Walls, S. D. Nunn, R. J. Ogle, and G. Westmoreland, "Development of low-toxicity gelcasting systems," Journal of the American Ceramic Society, vol. 81, no. 3, pp. 581-591, 1998.

[13] A. J. Millán, R. Moreno, and M. I. Nieto, “Thermogelling polysaccharides for aqueous gelcasting-part I: a comparative study of gelling additives," Journal of the European Ceramic Society, vol. 22, no. 13, pp. 2209-2215, 2002.
[14] Z. P. Xie, J. L. Yang, D. Huang, Y. L. Chen, and Y. Huang, "Gelation forming of ceramic compacts using agarose," British Ceramic Transactions, vol. 98, no. 2, pp. 58-61, 1999.

[15] Y. Chen, Z. Xie, J. Yang, and Y. Huang, "Alumina casting based on gelation of gelatine," Journal of the European Ceramic Society, vol. 19, no. 2, pp. 271-275, 1999.

[16] L. J. Vandeperre, A. M. de Wilde, and J. Luyten, "Gelatin gelcasting of ceramic components," Journal of Materials Processing Technology, vol. 135, no. 2-3, pp. 312-316, 2003.

[17] F. S. Ortega, F. A. O. Valenzuela, C. H. Scuracchio, and V. C. Pandolfelli, "Alternative gelling agents for the gelcasting of ceramic foams," Journal of the European Ceramic Society, vol. 23, no. 1, pp. 75-80, 2003.

[18] Y. Jia, Y. Kanno, and Z. P. Xie, "New gel-casting process for alumina ceramics based on gelation of alginate," Journal of the European Ceramic Society, vol. 22, no. 12, pp. 1911-1916, 2002.

[19] J. Wang, X. Wang, and W. Zhao, "Alumina gelcasting by using glutin-urea system," Advanced Materials Research, vol. 284-286, pp. 1423-1426, 2011.

[20] P. Bednarek, M. Szafran, Y. Sakka, and T. Mizerski, "Gelcasting of alumina with a new monomer synthesized from glucose," Journal of the European Ceramic Society, vol. 30, no. 8, pp. 17951801, 2010.

[21] S. Timoshenko, Strength of Materials, Part I, Elementary Theory and Problems, D. Van Nostrand Company, 3rd edition, 1955.

[22] A. J. Fanelli, R. D. Silvers, W. S. Frei, J. V. Burlew, and G. B. Marsh, "New aqueous injection molding process for ceramic powders," Journal of the American Ceramic Society, vol. 72, no. 10, pp. 1833-1836, 1989.

[23] P. Sepulveda, "Gelcasting foams for porous ceramics," American Ceramic Society Bulletin, vol. 76, no. 10, pp. 61-65, 1997.

[24] M. Lombardi, V. Naglieri, J. M. Tulliani, and L. Montanaro, "Gelcasting of dense and porous ceramics by using a natural gelatine," Journal of Porous Materials, vol. 16, no. 4, pp. 393-400, 2009.

[25] J. M. Tulliani, C. Bartuli, E. Bemporad, V. Naglieri, and M. Sebastiani, "Preparation and mechanical characterization of dense and porous zirconia produced by gel casting with gelatin as a gelling agent," Ceramics International, vol. 35, no. 6, pp. 2481-2491, 2009.

[26] C. Bartuli, E. Bemporad, J. M. Tulliani, J. Tirillò, G. Pulci, and M. Sebastiani, "Mechanical properties of cellular ceramics obtained by gel casting: characterization and modeling," Journal of the European Ceramic Society, vol. 29, no. 14, pp. 2979-2989, 2009.

[27] J. M. Tulliani, V. Naglieri, M. Lombardi, and L. Montanaro, "Porous alumina and zirconia bodies obtained by a novel gel casting process," in Proceedings of the 32nd International Conference \& Exposition on Advanced Ceramics and Composites, R. Narayan and P. Colombo, Eds., Daytona Beach, Fla, USA, 2008.

[28] M. Lombardi, L. Montanaro, L. Grémillard, and J. Chevalier, "New gelcasting procedure to prepare alumina porous components: process optimization and preliminary mechanical tests," in Proceedings of the 32nd International Conference \& Exposition on Advanced Ceramics and Composites, R. Narayan and P. Colombo, Eds., Daytona Beach, Fla, USA, 2008.

[29] W. C. Oliver and G. M. Pharr, "Improved technique for determining hardness and elastic modulus using load and displacement sensing indentation experiments," Journal of Materials Research, vol. 7, no. 6, pp. 1564-1580, 1992. 
[30] R. B. King, "Elastic analysis of some punch problems for a layered medium," International Journal of Solids and Structures, vol. 23, no. 12, pp. 1657-1664, 1987.

[31] O. Sahin, O. Uzun, U. Kölemen, and N. Uçar, "Mechanical characterization for $\beta$-Sn single crystals using nanoindentation tests," Materials Characterization, vol. 59, no. 4, pp. 427-434, 2008.

[32] W. C. Oliver and G. M. Pharr, "Measurement of hardness and elastic modulus by instrumented indentation: advances in understanding and refinements to methodology," Journal of Materials Research, vol. 19, no. 1, pp. 3-20, 2004.

[33] M. Troyon and L. Y. Huang, "Correction factor for contact area in nanoindentation measurements," Journal of Materials Research, vol. 20, no. 3, pp. 610-617, 2005.

[34] J. M. Tulliani, M. Lombardi, P. Palmero, M. Fornabaio, and L. J. Gibson, "Development and mechanical characterization of novel ceramic foams fabricated by gel-casting," Journal of the European Ceramic Society, vol. 33, no. 9, pp. 1567-1576, 2013.

[35] A. K. Gain, H. Y. Song, and B. T. Lee, "Microstructure and mechanical properties of porous yttria stabilized zirconia ceramic using poly methyl methacrylate powder," Scripta Materialia, vol. 54, no. 12, pp. 2081-2085, 2006.

[36] D. M. Owen and A. H. Chokshi, "The high temperature mechanical characteristics of superplastic $3 \mathrm{~mol} \%$ yttria stabilized zirconia," Acta Materialia, vol. 46, no. 2, pp. 667-679, 1998.

[37] M. Jiménez-Melendo, A. Domínguez-Rodríguez, and A. BravoLeón, "Superplastic flow of fine-grained yttria-stabilized zirconia polycrystals: constitutive equation and deformation mechanisms," Journal of the American Ceramic Society, vol. 81, no. 11, pp. 2761-2776, 1998.

[38] E. Zapata-Solvas, D. Gómez-García, C. García-Gañán, and A. Domínguez-Rodríguez, "High temperature creep behaviour of $4 \mathrm{~mol} \%$ yttria tetragonal zirconia polycrystals (4-YTZP) with grain sizes between 0.38 and $1.15 \mu \mathrm{m}$," Journal of the European Ceramic Society, vol. 27, no. 11, pp. 3325-3329, 2007.

[39] D. M. Owen and A. H. Chokshi, "Analysis of deformation mechanisms in superplastic yttria-stabilized tetragonal zirconia," International Journal of Plasticity, vol. 17, no. 3, pp. 353-368, 2001.

[40] K. Morita and K. Hiraga, "Critical assessment of high-temperature deformation and deformed microstructure in high-purity tetragonal zirconia containing $3 \mathrm{~mol}$ \% yttria," Acta Materialia, vol. 50, no. 5, pp. 1075-1085, 2002.

[41] J. Luo and R. Stevens, "Porosity-dependence of elastic moduli and hardness of 3Y-TZP ceramics," Ceramics International, vol. 25, no. 3, pp. 281-286, 1999. 

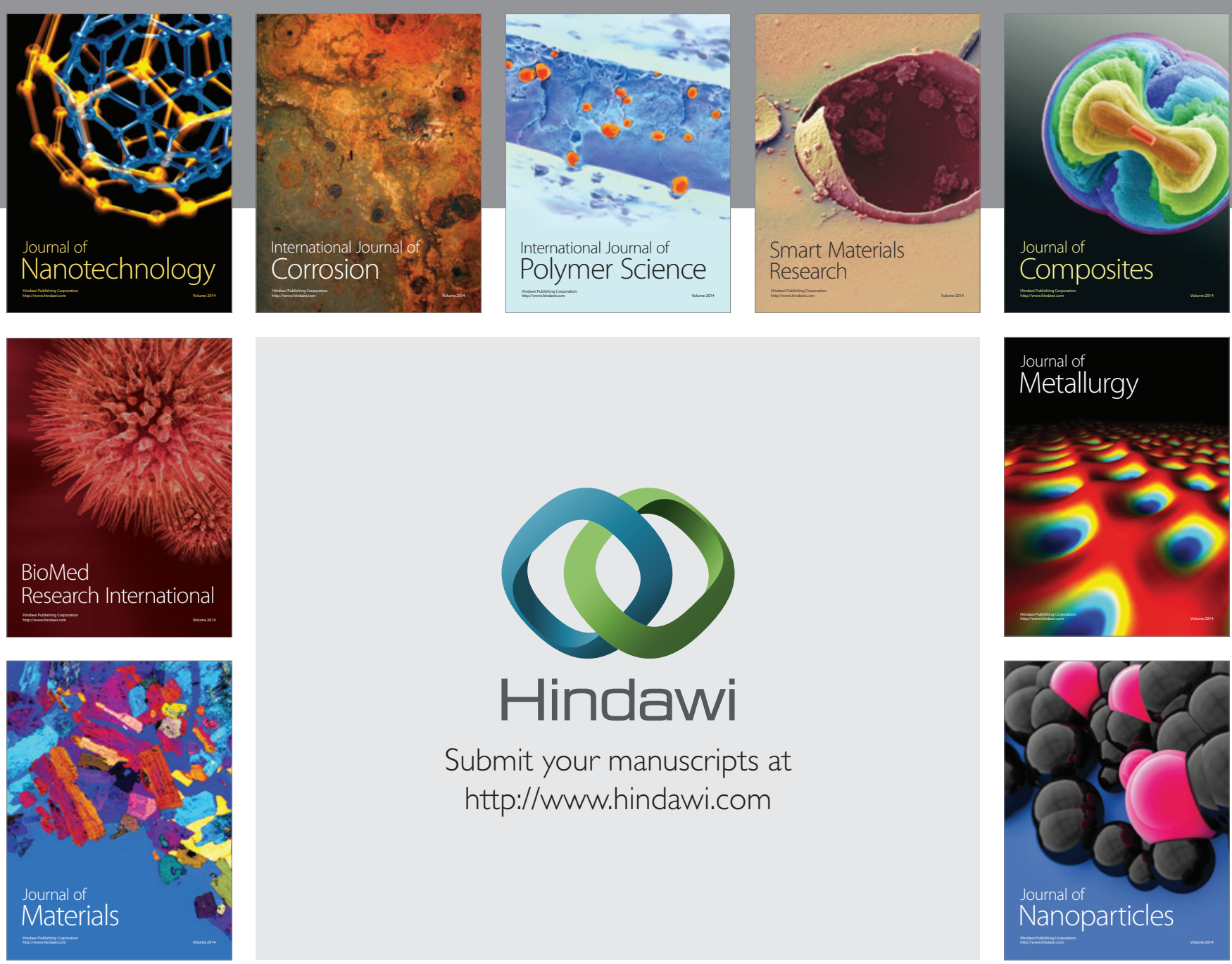

Submit your manuscripts at http://www.hindawi.com
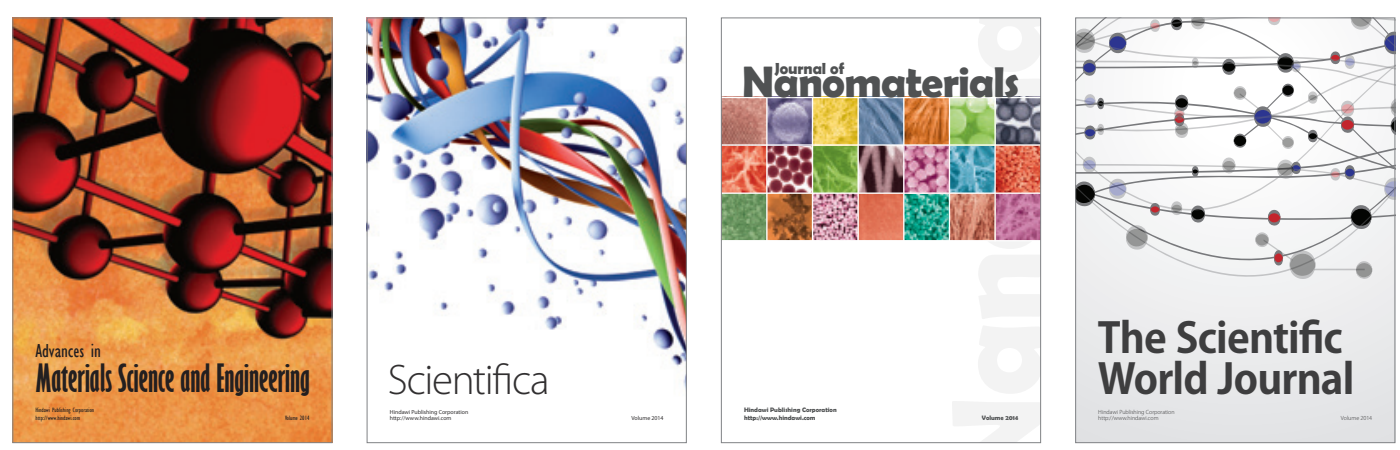

\section{The Scientific World Journal}
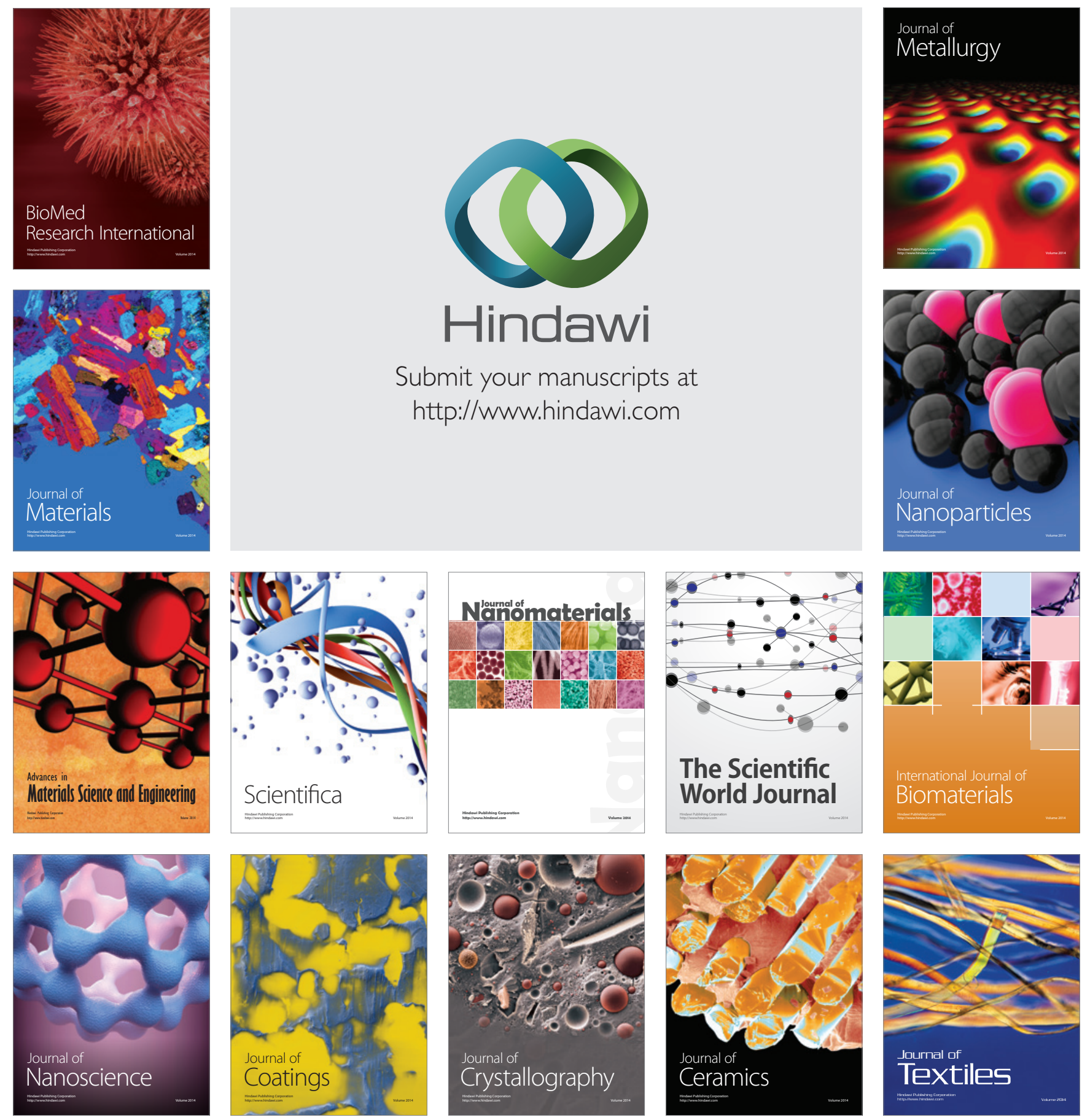